\section{Os caminhos do futebol praticado por mulheres no Brasil: entrevista com Silvana Goellner}

\section{Gabriel Canuto Nogueira da Gama}

Universidade Federal de Minas Gerais (UFMG), Belo Horizonte/Brasil Mestre em Estudos Literários, UFMG gabrielcngama@gmail.com

De tudo que vi e senti naqueles três dias de setembro de 2016, a segurança nos olhos da professora Silvana Vilodre Goellner, da UFRGS, foi o momento que mais me atravessou. Na função de jornalista responsável pela cobertura midiática da segunda edição do Simpósio Internacional Futebol, Linguagem, Artes, Cultura e Lazer, entrevistei uma dezena de eminentes pesquisadores sobre futebol no país. Dentre as profícuas conversas nos corredores do Museu Brasileiro de Futebol, sediado no Mineirão, não esqueço a força que emanava da fala de Silvana. Ela transbordava retidão.
Gaúcha, com formação na área de Educação Física pela UFSM, Doutora em Educação pela Unicamp e professora titular da UFRGS, Silvana é uma das principais referências no que tange aos estudos sobre mulheres no futebol brasileiro. Há décadas, debruça-se sobre o tema com afinco e vem propondo medidas, buscando soluções para lidar com o histórico preconceito subjacente à prática feminina nesse esporte.

No âmbito acadêmico, a pesquisadora tem atentado para as razões que acarretam a falta de visibilidade e de estrutura do futebol jogado por mulheres no Brasil em diversas publicações científicas. É coordenadora do Centro de Memória do Esporte da ESEF/UFRGS e do GRECCO - Grupo de Estudos sobre Esporte, Cultura e História. Fora de campo, sua representatividade se reflete no papel de curadora da exposição "Futebol e Mulheres no País da Copa de 2014", realizada em Porto Alegre, e cocuradora da exposição "Visibilidade para o Futebol Feminino", realizada no Museu do Futebol (2015). 
Nesta entrevista, Silvana nos enriquece com reflexões críticas acerca do panorama do nosso futebol praticado por mulheres. Aponta condições político-históricas - e até econômicas - que resultaram em uma problemática distinção entre a prática masculina e a feminina. Além disso, suscita questionamentos e prospecta ações, de fato, concretas a favor do protagonismo das mulheres - das jogadoras às árbitras - no futebol brasileiro.

Gabriel Gama: Em seus estudos relacionados ao futebol feminino no Brasil, você vem apontando possíveis razões para o iminente preconceito que existe acerca da prática entre mulheres, sobretudo, quando comparado ao jogo dos homens. Quais são as principais conclusões que têm chegado em suas pesquisas?

Silvana Vilodre Goellner: É importante frisar que não são apenas reflexões teóricas, mas há todo um envolvimento político. Quando se discute sobre as relações que existem entre o futebol feminino e o masculino, eu tenho pensado em três tipos de categorias. A primeira delas diz respeito à "biologização" das diferenças, ou seja, a um discurso bastante comum que justifica uma distinção entre o futebol praticado pelos homens e pelas mulheres com base nas diferenças biológicas. Segundo esse discurso, as mulheres são marcadas por limitações, tais como uma possível falta de vigor físico, a ausência de força, entre outras razões que, de certo modo, sugere falhas na própria estrutura corpórea delas.

No futebol, o discurso da biologia como grande demarcador da diferença entre homens e mulheres tem muita força e isso necessita de ser fissurado. Ideias como a masculinização das mulheres ainda são recorrentes, assim como a associação entre a prática do futebol e a homossexualidade em função da demanda desse esporte por atributos que, culturalmente, são considerados viris, como força e velocidade. Atributos vistos supostamente como exclusivos ao homem e que, ao serem observados em uma mulher, tencionam as representações do que seja masculino e feminino e o discurso que sustenta essas representações, ou seja, o de caráter biológico. 
A segunda ideia é uma certa assepsia da diversidade, ou seja, o fato de existir uma certa resistência à presença de mulheres de diferentes classes sociais, de distintas religiões, gerações, raças, etnias e orientações sexuais. O terceiro ponto é essa eterna comparação com os homens, o que prejudica o próprio desenvolvimento da modalidade, pois, quando está relacionado ao praticado pelos homens, o futebol das mulheres fica sempre subsumido a segundo plano.

Então, eu tentei levantar esses aspectos em minhas intervenções, visando subsidiar uma agenda político-pedagógica que abrangesse, desde o fomento de demandas junto às federações, a CBF e aos clubes, até em proposições que buscam a preservação da memória junto às universidades, aos museus e centros de memória.

Nessa agenda de pautas, estão sugestões como: a criação de um departamento feminino na CBF; a promoção de cursos específicos para treinadoras mulheres focando em uma profissionalização da carreira; o aporte em investimentos para as categorias de base; a veiculação dos jogos em transmissões de canais estatais; a aprovação de políticas públicas específicas; a criação de uma ouvidoria para casos de assédio e abuso sexual contra mulheres no futebol; a produção de registros de memória em acervos; e a separação de um percentual da arrecadação dos clubes para o investimento no futebol de mulheres.

Gabriel: A que você considera o amor volúvel que existe pelo futebol feminino?

Silvana: Penso que essa paixão efêmera existe pela própria estrutura do futebol de mulheres no Brasil. Esse amor é instantâneo, porque o sentimento surge em situações pontuais como em campeonatos muito curtos e restritos. Não existem clubes que invistam de uma maneira mais prolongada no futebol de mulheres, então, a modalidade só tem repercussão quando acontecem grandes eventos. Por exemplo, durante os Jogos Olímpicos de 2016, vimos uma projeção repentina na mídia da seleção feminina enquanto os homens não estavam bem. Depois, reverteu-se a história: quando o masculino foi campeão, as mulheres voltaram a ser renegadas. 
Quando são veiculadas matérias na mídia sobre o futebol feminino em competições de expressão, o público gosta, se encanta, interage, mas como há pouca estrutura e visibilidade nos campeonatos estaduais e locais, esse amor acaba diminuindo. Isso se dá porque o futebol de mulheres não é visto e, portanto, não é reconhecido. Carecemos ainda de uma estrutura mais profissional para as mulheres no futebol brasileiro.

Gabriel: Em algumas ocasiões, você já mencionou o fenômeno de embranquecimento da seleção brasileira feminina ao longo de sua história. A que se deve esse fenômeno?

Silvana: Não que exista uma causa específica, mas eu acredito que esse processo vem ocorrendo desde a década de 1980. Acredito que a erotização do futebol praticado por mulheres, recorrente em nosso país, vem do interesse mercadológico de atrair mais patrocínio, mais público. Uma das perspectivas que dá para observar na história do futebol feminino em nosso país é a valorização de uma dada representação de beleza que começa a ser utilizada para, digamos assim, "vender" o futebol. É importante ressaltar que, em alguns momentos históricos, as jogadoras tinham visibilidade somente por essa razão. A mídia, em grande medida, tenta normatizar as atletas a partir de uma erotização de seus corpos. Por vezes, fala-se muito mais da beleza ou da ausência de beleza das jogadoras do que de seus aspectos técnicos e táticos, de suas habilidades e de suas potencialidades no jogo.

Então, essa ideia de embranquecimento, essa referência de que o futebol feminino, hoje, é praticado por "mulheres bonitas", em comparação com as décadas anteriores, é atravessada pela ideia de transformar a modalidade feminina desse esporte em um produto vendável, comercializável. Mas, a gente não quer a beleza das jogadoras. A gente quer ver o jogo delas. Acrescento ainda o fato de que o racismo no Brasil é uma realidade e, neste contexto, os corpos negros "valem menos", são subvalorizados.

Gabriel: Você tem mencionado uma necessidade de haver mais pesquisas relacionadas aos marcos regulatórios históricos do futebol feminino, isto é, sobre o longo período 
de restrição à prática desse esporte pelas mulheres. É um tema emergente para os estudos?

Silvana: Eu penso que sim. Algumas modalidades esportivas, dentre elas o futebol, foram proibidas por aproximadamente 40 anos no país por meio do Decreto-Lei 3.199 do Conselho Nacional de Desportos. Esse Decreto foi revogado em 1979 e o futebol feminino regulamentado apenas em 1983. Ainda se fala muito pouco das mulheres no futebol, sobretudo, no meio acadêmico. Grande parte dos estudos sobre esse esporte no Brasil narram histórias e memórias de clubes e jogadores. Temos de mudar a perspectiva e falar mais do protagonismo das mulheres no futebol.

Na história oficial, elas praticamente não aparecem. É preciso que o futebol de mulheres seja pauta da nossa agenda política e pedagógica não só em tempos de Copa do Mundo, de Jogos Olímpicos ou, ainda, não somente quando o desempenho da seleção de homens está aquém do esperado e fala-se das mulheres na tentativa de fazer um contraponto. Elas merecem tratamento mais equânime.
Muitas pessoas desconhecem esse gap histórico, esse lapso enorme no desenvolvimento da modalidade. Acreditam que o futebol de mulheres teve, desde o início, o mesmo incentivo que o futebol dos homens. Não foi assim. A proibição do futebol para as mulheres marcou de forma muito profunda a cultura brasileira. A falta de incentivo dos pais em colocar as meninas para jogar, a ausência de times, a não oferta desse esporte na Educação Física escolar e nos programas de lazer, por exemplo, resultou em uma situação bastante prejudicial às mulheres.

Como não se conhece a história e, consequentemente, a arbitrária proibição, não se tem a dimensão de que o resultado que a gente tem hoje é em função desse silenciamento que venho dizendo. Mas, é importante pensar que o fato de a proibição oficial existir não significa que elas não jogavam. Elas sempre praticavam, mas viviam à margem. Não podiam disputar faixa preta no judô, não podiam disputar campeonato oficial, não podiam competir em provas de longa distância, etc. Então, eu acho interessante refletir sobre essa proibição para que o público saiba que houve, sim, um momento que, se elas jogassem futebol, iam presas. A polícia 
intervia e, com base no Decreto-Lei, acabava com o jogo porque oficialmente era proibido.

Gabriel: Quais ações são as mais importantes para uma agenda político-pedagógica em prol do futebol de mulheres e no combate à essa cultura machista que perpassa o âmbito esportivo em nossa sociedade?

Silvana: A primeira providência é visibilizar os clubes, as equipes, as atletas que hoje investem no futebol. Há também o futebol de várzea muito forte entre as mulheres que não aparece em lugar algum. Não se fala sobre ele. Precisamos visibilizar, mostrar que há um protagonismo. Acho que essa é uma primeira ação. A outra é que não podemos abandonar as mulheres no futebol. Elas possuem condições pouco dignas de trabalho: não há aposentadoria, plano de saúde, carteira assinada, entre outros benefícios de direito. Grande parte delas joga por amor, pela dedicação, por uma medíocre ajuda de custo.

Devemos, também, continuar torcendo por elas, não só durante os Jogos Olímpicos ou em outros grandes eventos, mas acessar o dia a dia das notícias do futebol feminino, acompanhar as outras competições, principalmente, as nacionais, ou seja, ver o que está, de fato, acontecendo. Temos de valorizar também o que vem sendo produzido e evidenciado na mídia sobre mulheres no futebol ainda que não seja o suficiente. Iniciativas como a grade de programas da ESPNW, extensão do canal de esportes ESPN, a coluna "Arquibancada" no portal Ludopédio, páginas em redes sociais como "Dibradoras" e exposições a exemplo de "Visibilidade para o futebol feminino" aberta ao público no Museu do Futebol, em São Paulo.

Acredito que, hoje, não tem outra tarefa senão lutar. Lutar sempre, temer jamais. De alguma maneira, é importante ir para os movimentos sociais, aderir a iniciativas que desejam a potencialização de grupos marginalizados e eu considero o grupo de mulheres como um deles. Eu penso o futebol delas como exercício de liberdade, de sociabilidade, de empoderamento.

Gabriel: Em 2015 e 2016, a exposição itinerante "Mulheres no futebol" ficou temporariamente no Museu Brasileiro do 
Futebol (MBF), localizado no Mineirão. Como que surgiu a ideia de criar um espaço memorialístico como esse para o futebol praticado por mulheres?

Silvana: Essa exposição itinerante foi em decorrência de uma outra que fizemos em 2015, no Museu do Futebol, no Estádio Pacaembu, intitulada "Visibilidade para o futebol feminino", que ficou aberta à visitação entre maio de 2015 a março de 2016. Essa ideia havia começado em Porto Alegre, durante a Copa do Mundo de 2014, quando o Centro de Memória do Esporte da UFRGS, que eu coordeno, organizou a exposição "Futebol para mulheres no país da Copa".

Em função dessa exposição e de outras intervenções que realizei, houve o contato com o Museu do Futebol e a aceitação de conceder, dentro do próprio Museu, um espaço para as mulheres. Então, a partir daí, fizemos uma exposição grande, inserindo as mulheres dentro da história do futebol e, o que é muito importante, dentro do acervo permanente do Museu do Futebol.
A ideia era contar a história delas, mostrar que, desde o início desse esporte, as mulheres estavam lá. Fizemos uma vasta pesquisa em jornais, museus, sites, e também contamos com materiais oriundos de acervos pessoais de várias atletas e treinadoras. Fizemos uma exposição com muitos artefatos. A opção foi construir alguns painéis, pensando na mobilidade da própria exposição, na possibilidade de circular em várias outras cidades do Brasil. Foi um trabalho que contribuiu para a reflexão do espaço memorialístico acerca do futebol feminino e de seus desdobramentos históricos. Várias ações foram desencadeadas a partir dessa visibilidade que a exposição teve no Pacaembu. Dentre elas, o contato realizado pelo Museu do Mineirão para trazer parte da exposição e, assim, valorizar a presença das mulheres no futebol brasileiro.

Gabriel: 0 público ainda pode ter acesso às peças da exposição no Museu do Futebol, no Pacaembu?

Silvana: Para quem for visitar o Museu do Futebol, é possível acessar alguns materiais que ficaram no acervo permanente, 
sobretudo, fotografias. 0 Centro de Referência do Museu do Futebol possui vários arquivos. Recentemente, a instituição começou a digitalizar o acervo de jogadoras, treinadoras e árbitras. Esses documentos inéditos podem ser encontrados tanto no site do Museu do Futebol quanto no LUMERepositório Digital da UFRGS e no Instituto Google via Museu do Futebol. Isso é importante ressaltar porque são iniciativas que atendem a ausência de registros. Como tenho dito: como reconhecer a importância das mulheres no futebol brasileiro se nem mesmo as conhecermos?

\section{***}

Entrevista concedida nos dias 09 e 10 de setembro de $2016 .{ }^{1}$

\footnotetext{
${ }^{1}$ O primeiro encontro foi gravado em vídeo para o canal do II Simpósio Internacional Futebol, Linguagem Artes e Lazer, na plataforma de vídeos YouTube. Disponível em: <https://bit.ly/2FZps|Q>.
}

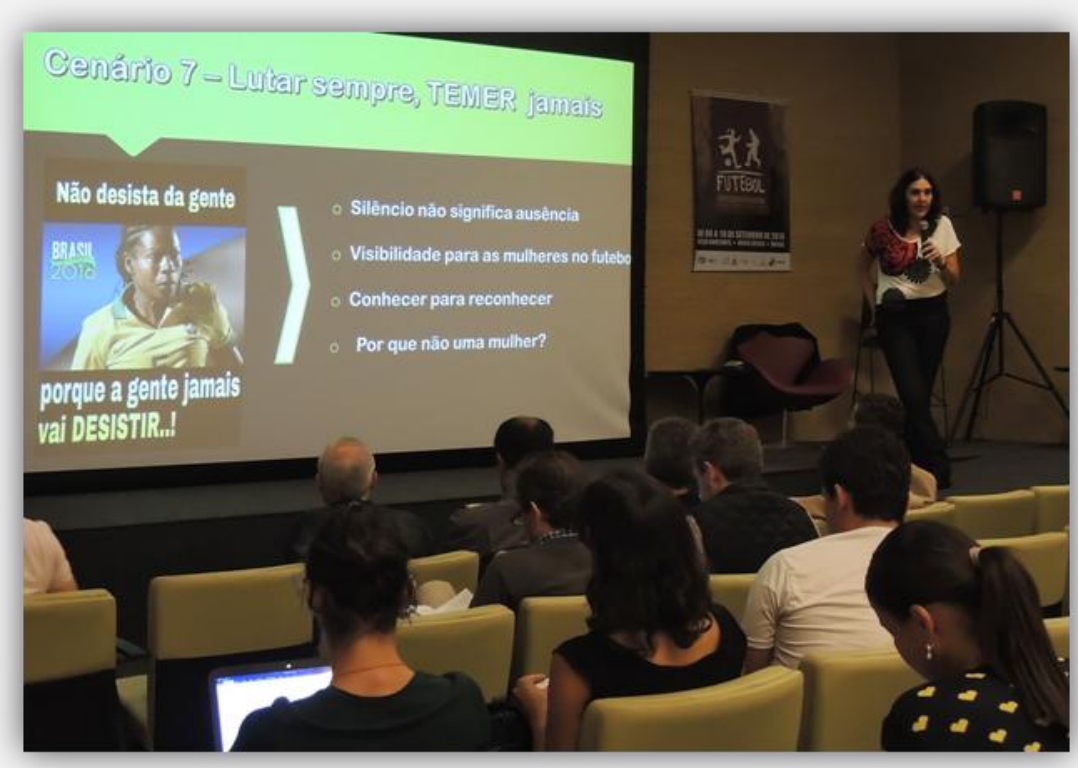

Silvana Goellner no Museu do Mineirão, em 2016. Imagem: Gabriel Gama. 